\title{
Review Article \\ Pain in Neurodegenerative Disease: Current Knowledge and Future Perspectives
}

\author{
Marina de Tommaso, ${ }^{1}$ Lars Arendt-Nielsen, ${ }^{2}$ Ruth Defrin, ${ }^{3}$ Miriam Kunz, \\ Gisele Pickering, ${ }^{5,6}$ and Massimiliano Valeriani ${ }^{2,7}$ \\ ${ }^{1}$ Neurophysiopathology of Pain Section, SMBNOS Department, Bari Aldo Moro University, Bari, Italy \\ ${ }^{2}$ Center for Sensory-Motor Interaction, Aalborg University, Aalborg, Denmark \\ ${ }^{3}$ Department of Physical Therapy, Sackler Faculty of Medicine, Tel-Aviv University, Tel-Aviv, Israel \\ ${ }^{4}$ Department of General Practice, Section Gerontology, University Medical Center Groningen, Groningen, Netherlands \\ ${ }^{5} \mathrm{CHU}$ Clermont-Ferrand, Centre de Pharmacologie Clinique, Clermont-Ferrand, France \\ ${ }^{6}$ Inserm, CIC 1405, Neurodol 1107, 63003 Clermont-Ferrand, France \\ ${ }^{7}$ Division of Neurology, Ospedale Pediatrico Bambino Gesù, IRCCS, Rome, Italy
}

Correspondence should be addressed to Marina de Tommaso; marina.detommaso@uniba.it

Received 10 January 2016; Revised 18 April 2016; Accepted 8 May 2016

Academic Editor: Andrea Truini

Copyright (C) 2016 Marina de Tommaso et al. This is an open access article distributed under the Creative Commons Attribution License, which permits unrestricted use, distribution, and reproduction in any medium, provided the original work is properly cited.

\begin{abstract}
Neurodegenerative diseases are going to increase as the life expectancy is getting longer. The management of neurodegenerative diseases such as Alzheimer's disease (AD) and other dementias, Parkinson's disease (PD) and PD related disorders, motor neuron diseases (MND), Huntington's disease (HD), spinocerebellar ataxia (SCA), and spinal muscular atrophy (SMA), is mainly addressed to motor and cognitive impairment, with special care to vital functions as breathing and feeding. Many of these patients complain of painful symptoms though their origin is variable, and their presence is frequently not considered in the treatment guidelines, leaving their management to the decision of the clinicians alone. However, studies focusing on pain frequency in such disorders suggest a high prevalence of pain in selected populations from 38 to $75 \%$ in $\mathrm{AD}, 40 \%$ to $86 \%$ in $\mathrm{PD}$, and 19 to $85 \%$ in MND. The methods of pain assessment vary between studies so the type of pain has been rarely reported. However, a prevalent nonneuropathic origin of pain emerged for MND and PD. In AD, no data on pain features are available. No controlled therapeutic trials and guidelines are currently available. Given the relevance of pain in neurodegenerative disorders, the comprehensive understanding of mechanisms and predisposing factors, the application and validation of specific scales, and new specific therapeutic trials are needed.
\end{abstract}

\section{Introduction}

Neurodegenerative diseases are going to increase in parallel to the lengthening of survival. The most common of them become more prevalent with age being accompanied by progressive motor and cognitive impairment. The management of neurodegenerative diseases as Alzheimer's disease (AD) and other dementias, Parkinson's disease (PD) and PD related disorders, motor neuron diseases (MND), Huntington's disease (HD), spinocerebellar ataxia (SCA), and spinal muscular atrophy (SMA), is mainly addressed to motor and cognitive impairment with special care to the vital functions as breathing and feeding. Many of these patients complain of painful symptoms though their origin is variable, and their presence is frequently not considered in the treatment guidelines, leaving their management to the decision of the clinicians alone. In some neurodegenerative diseases as Parkinson's disease, pain has recently been recognized as a frequent and invalidating symptom [1]. In general, pain treatment should mainly be based on its pathophysiological mechanisms. According to the International Association for the Study of Pain (IASP), pain is an unpleasant sensory and emotional experience associated with actual or potential tissue damage or described in terms of such damage [2]. Most pain syndromes are neuropathic or nociceptive in their origin. While central and peripheral neuropathic pain are caused by a lesion 
or disease of the central or peripheral somatosensory nervous system, respectively, the nociceptive pain arises from actual or threatened damage to nonneural tissue and is due to the activation of nociceptors [3]. Thus, nociceptive pain occurs in patients with a normally functioning somatosensory nervous system [3]. Neurodegeneration may specifically involve the somatosensory system, thus making a neuropathic origin of pain very likely, or it may affect cortical and subcortical structures involved in pain modulation. Motor impairment with muscular tone abnormalities and reduced active mobility may cause osteoarticular problems with local inflammation and nociceptive pain. In many neurodegenerative conditions, the origin of pain is complex, often multifactorial and hardly classifiable as merely neuropathic or nociceptive. In addition, there are few evidences on frequency and characteristics of pain symptoms in neurodegenerative disorders and on their impact on the disease outcome. An IASP task force [4] has revised the clinical and instrumental assessment of chronic pain as well as its therapeutic management so a systematic application of these guidelines to chronic pain in neurodegenerative diseases should be within reach. However, pain assessment may be hampered by the impairment of cognitive and motor performances so special recommendation should be provided upon approaching this important aspect of neurodegenerative diseases.

The present review focuses on chronic pain in main neurodegenerative diseases addressing the current knowledge about pain frequency and clinical features, clinical and instrumental assessment, possible pathophysiological mechanisms, and the current evidence on pain therapeutic management. Also the main limitations of the present studies and the future research direction and perspectives are considered.

We also dedicated a section to rare neurodegenerative conditions where pain was not extensively assessed.

This was a narrative review based on PubMed search by the following key words: pain, pain frequency, pain features, pain treatment and Alzheimer disease, Parkinson's disease, extrapyramidal disorders, motor neuron disease, and spinocerebellar ataxia. There was no time limit for the research, starting form the first date reported by PubMed.

\section{Alzheimer Disease and Other Dementias}

Dementia refers to a broad category of brain neurodegenerative diseases that are accompanied by loss of ability in memory function, attention, executive function, orientation, language, and other cognitive domains as well as by changes in mood and behavior, which increase across the course of dementia. There are an estimated 35 million people with dementia in the world. The most common type of dementia is Alzheimer's disease. Other forms of dementia are vascular dementia, frontotemporal dementia, and Lewy body dementia. Given that the prevalence rate of dementia is tightly linked to ageing, the increase of ageing population is the main reason for the predicted substantial growth in the number of people affected by dementia. Not only do prevalence rates of dementia increase with age, but also the prevalence rates of pain are strongly linked to ageing [5]. Given that both the prevalence rates of dementia and pain increase with age, it appears that pain is highly common among people suffering from dementia. The difficulty is, however, that patients with dementia (particularly those in the advanced stages of the disease) are often unable to use self-report to communicate their suffering, and thus their pain is often overlooked and remains untreated [6].

2.1. Pain Frequency and Clinical Features. Due to their advanced age, individuals with dementia often suffer from multiple morbidities associated with pain. However, the exact pain prevalence in dementia is unknown due to the lack of self-report in this patient group as mentioned previously. Studies using observational tools to assess pain indicate that about $50 \%$ of patients with dementia living in nursing homes are suffering from pain $[13,28]$. This is in line with prevalence rates reported about nursing home patients, independently of their cognitive status. Yet, the prevalence of pain among patients with dementia is associated with the severity of the condition. In fact, between $45 \%$ and $83 \%$ of the patients living in nursing homes experience acute or chronic pain [29]. Most of these patients (about 94\%) were reported to suffer from persistent pain (3-6 months or more). The causes of pain among patients with dementia living in nursing homes include but are not restricted to genitourinary infections, pathologies in the musculoskeletal system [30], pressure ulcers [31], and skin diseases, with the latter of which found in $95 \%$ of the patients and described as one of the most prevalent health problems in this population [32].

Several studies have estimated the prevalence rates of pain among patients with dementia who are living at home. These prevalence rates are listed in Table 1 [7-13]. What appears evident is that the rates vary across studies, depending on whether they are based on the self-report or on the caregivers' report. Overall, at least $50 \%$ of the community dwelling patients with dementia seem to be suffering from pain. Considering the aforementioned studies, pain is highly prevalent among patients with dementia whether living in nursing homes or living at home, and thus its management required careful assessment and monitoring.

2.2. Clinical and Instrumental Assessment. Given the high prevalence of pain in the elderly, proper assessment of pain by observers such as health care professionals or family members is required for successful pain treatment. Due to the subjective and complex nature of the pain experience, assessing patients' pain is often a challenge. The more severe the cognitive impairment is and hence the more severe the loss of self-report is, the greater the challenge is [33]. In such instances, caregivers should rely less on self-report and more on behavioral indicators of pain. Facial expressions in particular seem to provide a valid indication of the patients' pain. Patients with dementia display the same types of facial movements in response to pain as cognitively intact individuals $[34,35]$. Thus, the pain-peculiarity of their facial expression is not reduced. This finding implies that facial expressions of pain have the potential to serve as an alternative pain indicator in patients with dementia. Other means to indirectly assess pain are various behavior rating scales (for comprehensive reviews, see, e.g., Herr et al. [36] 
TABLE 1: Summary of the studies on the prevalence of pain among patients with dementia living at home or in nursing homes. Features and location of pain were not available.

\begin{tabular}{|c|c|c|c|c|}
\hline & Study design & $\begin{array}{c}\text { Number of patients and } \\
\text { controls }\end{array}$ & Assessment method & Frequency of pain \\
\hline Barry et al. [7] & Observational & $\begin{array}{l}\text { Patients: } 75 \\
\text { Controls: } 0\end{array}$ & Interview with patients and caregivers & $\begin{array}{l}\text { Daily pain } \\
\text { Patients' report: } 57 \% \\
\text { Caregivers' report: } 71 \%\end{array}$ \\
\hline Barry et al. [8] & Observational & $\begin{array}{l}\text { Patients: } 42 \\
\text { Controls: } 0\end{array}$ & Interview with patients, nurses, and relatives & $\begin{array}{l}\text { Daily pain } \\
\text { Patients' report: } 38 \% \\
\text { Nurses' report: } 69 \% \\
\text { Relatives' report: } 75 \%\end{array}$ \\
\hline Hunt et al. [9] & Observational & $\begin{array}{l}\text { Patients: } 802 \\
\text { Controls: } 802\end{array}$ & Interview with patients & $\begin{array}{l}\text { Bothersome pain } \\
\text { Patients' report: } 64 \% \\
\text { Controls' report: } 55 \%\end{array}$ \\
\hline Werner et al. [10] & Observational & $\begin{array}{l}\text { Patients: } 141 \\
\text { Controls: } 55\end{array}$ & Category rating scale & $\begin{array}{l}\text { Pain is experienced } \\
\text { Patients' report: } 21 \% \\
\text { Patients' and Caregivers' } \\
\text { report: } 46 \% \\
\text { Controls' report: } 48.1\end{array}$ \\
\hline Mäntyselkä et al. [11] & Observational & $\begin{array}{l}\text { Patients: } 75 \\
\text { Controls: } 446\end{array}$ & Interview with the patients & $\begin{array}{l}\text { Any pain } \\
\text { Patients' report: } 43 \% \\
\text { Controls' report: } 69 \%\end{array}$ \\
\hline Shega et al. [12] & Observational & $\begin{array}{l}\text { Patients: } 150 \\
\text { Controls: } 0\end{array}$ & Interview with patients and caregivers & $\begin{array}{l}\text { Pain right now } \\
\text { Patients' report: } 32 \% \\
\text { Caregivers' report: } 52 \%\end{array}$ \\
\hline Zwakhalen et al. [13] & Observational & $\begin{array}{l}\text { Patients: } 117 \\
\text { Controls: } 0\end{array}$ & Observational pain scale & $\begin{array}{l}\text { Experience of pain to some } \\
\text { extent } \\
\text { Nurses' observations: } 47 \%\end{array}$ \\
\hline
\end{tabular}

and Zwakhalen et al. [13]). However, the validation process of these scales has just started. Although the first results are promising, future studies are needed to define which items are able to discriminate between pain behavior and behaviors related to other aspects of unmet needs in patients with dementia. Within a European initiative (COST TD1005), researchers across Europe have started to investigate which behavioral items can indeed validly indicate the presence of pain in patients with different types of cognitive impairment. The process is still ongoing [37] but will hopefully be completed within the next 1-2 years.

2.3. Possible Pathophysiological Mechanisms. Only a few experimental studies have tried to investigate how dementia affects the processing of nociceptive information with most studies focusing on patients with Alzheimer's disease (for a comprehensive review, see Defrin et al. [38]). Alarmingly, the majority of the experimental findings seem to suggest that the processing and the experience of pain are not diminished in patients with mild-to-moderate forms of dementia. On the contrary, the pain experience might even be enhanced. It has been reported that patients with dementia respond to noxious stimulation with more enhanced facial responses [34, 35] and pain withdrawal reflexes [35] compared with cognitively intact peers. Functional magnetic resonance imaging (fMRI) studies showed that brain activity in response to noxious stimulation is preserved and even elevated in patients with mild forms of Alzheimer's disease [39, 40] corroborating findings based on facial and reflexive expressions. Using evoked related potentials (ERPs), one study found no difference in peak amplitude between patients and controls [41] and one study failed to induce pain-evoked potentials in the subgroup of patients with severe dementia [42]. The widespread brain damage occurring in the course of dementia might possibly affect descending pain modulation pathways most strongly in mild-to-moderate stages of dementia, which in turn lead to reduced inhibitory control over the pain system and increased pain processing. In later stages of dementia, the ascending pain pathways might be affected more severely, resulting in reduced pain processing. However, this is only speculative since research on patients at severe stages of dementia is lacking.

\subsection{Current Evidence on Pain Therapeutic Management.}

Recent reviews on pain management in patients with dementia point to a severe lack of effective assessment and treatment in different clinical settings and to the conclusion that even today patients with dementia are still undertreated for pain compared with nondemented elderly individuals $[43,44]$. However, this seems to be slowly changing. Two studies from Scandinavia $[45,46]$ found that patients with dementia received even more analgesic drugs (mostly paracetamol) compared with those without dementia. The increased dosage was administered even though the patients reported pain less frequently, and the prevalence of the pain related diagnoses was similar compared with persons without 
dementia. Beyond being very promising, these results clearly suggest that the research findings of the last decadeswhich reported an undertreatment of pain in dementiahave already impacted the clinical practice and have led to an intensification of pain management in this frail patient group.

2.5. Main Limitations of the Present Studies and Future Directions. In the last two decades, much effort has been invested to better understand how dementia affects the pain processing as well as its assessment. Up to now, an impressive number of pain behavior rating scales have been developed trying to assess pain based on nonverbal behavior. However, the validity, usability, and feasibility of these scales are still unsatisfactory, and they are not often used in the clinical practice. Moreover, dementia is a very broad concept that includes not only various types of neurodegenerative processes affecting different brain areas but also different degrees of cognitive decline. Most studies do not differentiate between different types or stages of dementia. Moreover, research investigating patients with dementia at the last stage of the disease is still mostly lacking, and, therefore, we do not know how pain processing might be altered in these very fragile patients. Moreover, it is an alarming fact that patients with dementia are still excluded from high quality randomized controlled trials of pain treatment. This underlines the comprehensive need of research as well as excellent implementation concepts for pain assessment and pain treatment in elderly individuals with dementia.

\section{Parkinson's Disease and Other Extrapyramidal Disorders}

Patients with Parkinson's disease (PD) often experience pain. By now, pain is commonly accepted to represent one of the PD nonmotor symptoms having a remarkable impact on the PD patients' quality of life. While pain was considered initially as an epiphenomenon of the motor impairment characteristic of the disease, the attention toward this symptom has increased in the last ten years. Two main elements led clinical and research efforts to understand the pain mechanisms in PD: (1) the higher prevalence of pain in PD patients compared to that in the healthy elderly subjects and (2) the involvement of nondystonic body parts, which means that pain is possibly linked to the intrinsic pathophysiological mechanisms of the disease.

3.1. Pain Frequency and Clinical Features. Pain in PD is commonly assessed according to Ford's scheme [47]. Five different types of pain can be recognized: (1) musculoskeletal, (2) radicular-neuropathic, (3) dystonic, (4) central neuropathic, and (5) akathisia pain. Whether the classical distinction between the nociceptive and the neuropathic pain is used or not, most Parkinsonian patients refer a nociceptive pain, which can be mainly musculoskeletal and visceral. Musculoskeletal pain derives from abnormal postures of the dystonic body parts, rigidity, and akinesia. Visceral pain is often the consequence of the abnormal function of the vegetative nervous system typical of the disease [48]. In
$\mathrm{PD}$, an example of neuropathic pain is represented caused by nerve root irritation following the abnormal posture and motor activity of the Parkinsonian patients. However, most papers on PD pain consider also a far less defined "central neuropathic" pain. This is poorly localized and often described as "boring," "constant," and "burning" [49]. The classification of this "central pain" is questionable according to the commonly accepted definition of neuropathic pain as being due to a lesion or a disease of the somatosensory system [3]. Although a clear sensory deficit cannot be demonstrated in PD patients with central pain, there are evidences linking this kind of pain to basal ganglia dysfunctions [50] and abnormal nociception [51].

Although several studies investigated the epidemiologic characteristic of pain in PD, the exact prevalence of this disabling symptom is not definitely known, ranging from $30 \%$ to $80 \%$ [49]. A recent meta-analysis [52] identified 8 studies which met the criteria of the Quality Assessment of Diagnostic Accuracy Studies (QUADAS) tool. In these studies, the average prevalence of pain was $67.6 \%$, ranging from $40 \%$ to $85 \%$. As for the location, the pain was prevalently referred to the lower limbs (47.2\%) while it involved less frequently the back (14.3\%), the upper limbs (13.4\%), and the neck/shoulder region $(12.4 \%)$. The most frequently reported type of pain was the musculoskeletal one (46\%) followed by dystonic (19.6\%) and radicular (9.1\%) pain. Central neuropathic pain was found in $5.6 \%$ of $\mathrm{PD}$ patients. Interestingly, the only available community study performed in Norway by Beiske et al. [1] reports the highest prevalence of pain in $\mathrm{PD}$ as compared to healthy subjects ( $83 \%$ versus $30 \%$ ). Valkovic et al. [16] have very recently investigated the modifications in the prevalence of pain during the disease progression. Interestingly, all the 4 Parkinson-related types of pain considered in this study (musculoskeletal, dystonic, radicular, and neuropathic) were more prevalent in the advanced stages of PD confirming their strict relationship with the disease.

It should be mentioned that a couple of studies failed in showing a higher prevalence of pain in PD patients compared to that in healthy subjects $[53,54]$. In these studies, however, the prevalence of pain was very low in PD patients as compared to other studies or high in healthy subjects thus suggesting an ascertainment bias [15] (Table 2).

3.2. Clinical and Instrumental Assessment. Though pain is very prevalent in $\mathrm{PD}$, in most studies rating scales not specific for this disease were used. Only a very recent multicenter study published the first PD pain specific scale [55]. King's Parkinson's Disease Pain Scale (KPPS) is an interview-based scale used to explore the frequency, intensity, and location of each type of $\mathrm{PD}$ pain. Moreover, it also rates the pain modifications associated with motor fluctuations in PD.

3.3. Possible Pathophysiological Mechanisms. Although the epidemiological data support the linkage between at least certain types of pain and the biological background of the disease, the pathophysiological mechanisms of pain in $\mathrm{PD}$ patients are far from being ascertained. According to the current idea, abnormal nociceptive mechanisms, which could 
TABLE 2: Summary of studies on the prevalence and features of pain among patients with Parkinson's disease.

\begin{tabular}{|c|c|c|c|c|c|}
\hline & Study design & $\begin{array}{l}\text { Number of } \\
\text { patients and } \\
\text { controls }\end{array}$ & Assessment methods & Frequency of pain & Feature and location of pain \\
\hline Nègre-Pagès et al. [14] & Observational & 450 & Visual analogue scale & 278 patients $(61.8 \%)$ & $\begin{array}{l}\text { PD related (167 patients) } \\
\text { Other types (111 patients) }\end{array}$ \\
\hline Defazio et al. [15] & Case control & 402 & Visual analogue scale & $\begin{array}{l}281 \text { patients }(69.9 \%) \text { and } \\
199 \text { controls }(62.8 \%)\end{array}$ & $\begin{array}{c}\text { Nondystonic (267 patients) } \\
\text { Dystonic and nondystonic } \\
\text { (14 patients) }\end{array}$ \\
\hline Beiske et al. [1] & Observational & 176 & $\begin{array}{l}\text { Structured interview } \\
\text { (SF-36) }\end{array}$ & 147 patients (83\%) & $\begin{array}{c}\text { Musculoskeletal (103 } \\
\text { patients) } \\
\text { Dystonic (59 patients) } \\
\text { Radicular (0 patients) } \\
\text { Central (15 patients) }\end{array}$ \\
\hline Valkovic et al. [16] & Observational & 100 & $\begin{array}{l}\text { Brief Pain Inventory } \\
\text { Leeds assessment of } \\
\text { neuropathic symptoms } \\
\text { and signs }\end{array}$ & 76 patients ( $76 \%)$ & $\begin{array}{c}\text { Musculoskeletal (41\%) } \\
\text { Radicular }(27 \%) \\
\text { Central }(22 \%) \\
\text { Dystonic }(17 \%) \\
\text { Others }(31 \%) \\
\end{array}$ \\
\hline Tinazzi et al. [17] & Observational & 117 & Visual analogue scale & 47 patients ( $40 \%)$ & $\begin{array}{l}\text { Dystonic (19 patients) } \\
\text { Musculoskeletal (22 } \\
\text { patients) } \\
\text { Radicular (4 patients) } \\
\text { Central (2 patients) }\end{array}$ \\
\hline
\end{tabular}

predispose patients to develop spontaneous pain, could be found in PD. This is suggested by psychophysical and neurophysiologic studies in PD patients without pain [15]. Reduced thresholds to different pain modalities were found in PD patients without pain compared with the control subjects [17, 51, 56-63]. Moreover, the laser evoked potential (LEP) amplitude assessing the pain matrix function was reduced in the pain-free PD patients [51] even in the early stages of the disease [58]. As for the role of dopamine in the development of PD pain, the available results are not univocal. Indeed, elements suggesting dopamine importance are represented by the more frequent involvement of the affected side in hemi-Parkinson and the pain modifications according to the PD motor fluctuations $[14,64]$. However, the psychophysical and neurophysiologic abnormalities shown in PD patients cannot generally recover after dopamine administration [65]. Monoaminergic systems different from the dopaminergic one could be involved in the pathophysiology of pain in PD.

Finally, it is worth mentioning that a reduction of small unmyelinated fibers was reported in PD both in the skin biopsy [66] and in cornea [67]. However, the meaning of the peripheral fiber reduction in the neurophysiological findings is not clear since the last ones seem most dependent on central nervous system modifications.

3.4. Current Evidence on Pain Therapeutic Management. No systematic study on pain treatment in PD is currently available. However, it is conceivable that the treatment strongly depends on the type of pain. Broen et al. [52] reviewed 3 studies, which provided some data. According to them, $37.6 \%$ of the PD patients use nonopioid analgesic while $13.5 \%$ of them use opioids and $11.8 \%$ of them use antidepressant and/or anticonvulsive drugs. Kass-Iliyya et al. [67] described an analgesic effect of the deep brain stimulation (DBS) indicated for the improvement of the motor symptoms. Eight patients, having undergone DBS electrode implant within the subthalamic nucleus, showed an increase of the pain threshold when the DBS was switched on as compared to what happened with the stimulator off. Moreover, the authors used the positron emission tomography to investigate the cerebral activity related to central neuropathic pain in $\mathrm{PD}$ patients. It was found that the DBS could reduce the brain activity related to pain.

\subsection{Main Limitations of Present Studies and Future Direction.} In conclusion, pain in PD has become an important element to be considered in the clinical practice since it can worsen the general impairment of the patients. In spite of the number of papers published in the last years, there are still some points which should be improved. Firstly, there is still the tendency to consider the different types of PD pain together in many studies. This can prevent the correct identification of the pathophysiological mechanisms and the best treatments that are unlikely to be the same for musculoskeletal, dystonic, and neuropathic pain. Secondly, the KPPS, which represents the first specific PD pain scale, was published in 2016 [55] while pain was previously assessed on the basis of the examiner's experience or by using some questionnaires not specific for PD. This has surely hampered a systematic classification of pain in $\mathrm{PD}$, which represents the mandatory background for any effective treatment.

\section{Other Extrapyramidal Disorders}

Although pain is often reported by patients with extrapyramidal disorders different from PD, there are only few studies 
dealing with pain in these conditions. Few studies dealt with pain frequency and features in patients with Huntington's disease (HD). Some clinical reports suggested that pain may not be sufficiently manifested and treated in HD patients and that it may be an underestimated problem $[68,69]$. In a study conducted by laser evoked potentials, HD patients in the early stages of the disease showed increased LEPs latencies, inversely correlated with their functional capacities [70]. In that study, only 3 out of 28 patients complained of pain despite the presence of possible postural and muscle skeletal abnormalities. This preliminary observation may support the need of more extensive multicentric observational controlled studies. There is a consistent amount of studies indicating that HD patients show a deficit in recognizing negative emotions and pain of others $[71,72]$. The impaired processing of negative experiences may thus be supported by an altered influence of basal ganglia on cortical areas devoted to the elaboration of stimuli requesting an aversive motor response as in the case of painful stimuli [73]. The disturbed processing of negative stimuli including pain may interfere with sensorymotor integration $[70,74]$ and contribute to the global worsening of the disease as suggested by the correlation found between LEPs abnormalities and disability in HD patients [70].

Some data have been collected for Cervical Dystonia $(\mathrm{CD})$, which is characterized by involuntary twisting neck movements and abnormal head postures [75]. Early studies reported pain in around $70 \%$ of $\mathrm{CD}$ patients $[76,77]$. More recently, Charles et al. [78] published epidemiological data from 1,037 CD patients included in a USA registry (Cervical Dystonia Patient Registry for Observation of OnabotulinumtoxinA efficacy-CD PROBE). At baseline, that is, before OnabotulinumtoxinA treatment, $88.9 \%(922 / 1037)$ of the patients reported pain related to CD. In particular, $70.7 \%$ (733/1037) reported moderate or severe pain intensity while $29.3 \%$ (304/1037) reported no pain or had only a mild pain intensity. Interestingly, the patients with no/mild pain were older than those with moderate/severe pain, while no difference between groups was found in the onset age or the duration of the disease. Unfortunately, no systematic pain classification, including also a possible separation between different types of pain (according to the model reviewed above for pain in PD), has been performed in CD. This contributes to the uncertainty about the pathophysiological mechanisms subtending pain in this condition. Indeed, it is conceivable that pain in $\mathrm{CD}$ can be due to the abnormal contraction of the dystonic muscles. However, this possibility has been challenged by the observation that botulinum toxin treatment does not always reduce pain [79, 80]. Moreover, pain is not always correlated with the severity of dystonia in the neck muscles [81]. These elements could lead to hypothesizing a susceptibility of the nociceptive system in CD similar to that demonstrated in PD. Tinazzi et al. $[82,83]$ recorded LEPs in $20 \mathrm{CD}$ patients by stimulating the skin overlying both painful and nonpainful muscles. They failed to show any abnormality of the nociceptive input processing in these patients making the hypothesis of a central sensitization of the pain matrix in $\mathrm{CD}$ unlikely. However, it has to be mentioned that partially different results were obtained in patients with nonpainful hand dystonia by using the contact heat evoked potentials (CHEPs) [84]. Indeed, 6 out of 10 patients showed reduced amplitude of their pain related brain responses to stimulation of the dystonic hand.

Pain was described as a common symptom also in multiple system atrophy (MSA) $[85,86]$. This finding was confirmed by a more recent study comparing 21 MSA patients with 65 PD patients [87]. Pain prevalence was similar between MSA (81\%) and PD (89\%) patients, as well as the scarce response of pain to dopamine administration in both conditions. In MSA, the pathophysiology of pain could be similar to that in PD, involving basal ganglia degeneration. This is suggested by the results of a neurophysiological study exploring pain processing in MSA and PD patients by using the nociceptive withdrawal reflex (NWR) recording [88]. MSA patients showed facilitation of a series of pain responses as compared to healthy subjects. However, no difference was found between MSA and PD patients in terms of neurophysiological abnormalities.

The progressive supranuclear palsy (PSP) is even less investigated than the previously reviewed conditions. The few available data suggest that pain in PSP is far less prevalent than that in PD $[87,88]$. However, the only neurophysiological study in PSP showed a lower pain threshold in PSP patients than that in control subjects suggesting that the apparently low prevalence of pain in this condition could be related to the early cognitive impairment of the patients [88].

\section{Motor Neuron Disease: Amyotrophic Lateral Sclerosis}

Amyotrophic lateral sclerosis (ALS), also known as motor neuron disease (MND), is the most common neurodegenerative disorder of the motor system in adults. ALS is characterized by a degeneration of primary motor neurons in the cortex, brainstem, and spinal cord. The amyotrophy (atrophy of muscle fibers) leads to muscular paralysis due to loss of innervating motor neurons. The lateral sclerosis typical of the disease refers to the upper motor neuron axonal loss and the hardening of corticospinal tracts and the resultant gliosis $[89,90]$. These changes can lead to a number of debilitating conditions that reflect aberrant functioning in both upper and lower motor neurons. These characteristic features of ALS are also accompanied by a number of secondary conditions that can be just as burdensome as those symptoms directly associated with the disorder. Although degeneration of motor neurons is pivotal in ALS, it is actually considered a multisystemic disorder involving sensory system. A spinocerebellar pathway (Clarke's column) taking origin in the spinal cord segments is consistently affected in pathological studies of ALS, which may underlie the early symptom of impaired balance often reported by patients at diagnosis [90]. In addition, clinicians have long noted minor sensory and autonomic involvement in patients with ALS [91] and small fiber neuropathy was found in skin biopsies in 79\% of ALS patients [92]. The link between ALS and frontotemporal dementia represents an extension of ALS as a motor system disease to the frontal and temporal 
lobes, which are brain areas involved in the expression of thought, planning, personality, and speech, all aspects of brain function that may interfere with pain perception [93]. The complexity of ALS pathophysiology and clinical appearance justifies the need to manage associate symptoms including pain.

5.1. Pain Frequency and Clinical Features. Thirty years ago, pain was reported to occur in ASL patients [94]. In the following years, some studies dealt with the frequency of pain in ALS patients, though most of them were conducted in small cohorts of patients in different stages of the disease; in addition, the case control design was sometimes omitted. In most studies, the usual classification in nociceptive and/or neuropathic pain was not used. Ganzini et al. [18] evaluated pain in ALS patients with direct interviews and questionnaires to caregivers. They found that both methods showed high representation of painful symptoms as causes of invalidity (Table 3). A case control study on neuromuscular diseases found that pain was present in $73 \%$ of the total population (193 patients) with ALS patients showing the greatest pain interference [19]. The pain was especially located in the back and shoulder, followed by neck, buttock and hip(s), feet, $\operatorname{arm}(s)$, and hand(s) [19]. Shoulder pain was also observed in 43 out of 193 ALS patients, independently of age, gender, and phenotype [20].

In a case control study, Chiò et al. [21] found that ALS patients reported pain more frequently than control subjects. Pain was correlated with the disease stage and invalidity. In an observational study on a small ALS series (42 patients), 19 experienced pain, which worsened the quality of life [22]. Rivera et al. [23] used the neuropathic pain scale [95] to study pain in 63 ALS patients in different stages of the disease. They found that about half of patients reported neuropathic pain, which was invalidating since it was present even in the early stages of the disease (Table 1). Pizzimenti et al. [24] observed pain in $72 \%$ of 36 ALS patients causing depression and a significant decline of the quality of life. More recently, Wallace et al. [25] specified that in $81 \%$ of 41 ALS patients complaining of pain this did not have neuropathic characteristics. In another recent study, 78\% of the examined patients complained about pain, which interfered with the quality of life, sleep, and mood [26]. The lack of correlation between severity of pain and disease duration was also reported in this latter study (Table 3). Another study applied the DN4 test for neuropathic pain scoring [96] in 92 ALS patients, who reported only rare symptoms of neuropathic origin [27]. Summarizing, both observational and case control studies reported a high frequency of pain in ALS patients from around $20 \%$ in retrospective studies to $80 \%$ in case control ones. Characteristics of pain symptoms have been collected with different scales though the most recent studies seemed to suggest the nonneuropathic origin of pain.

5.2. Clinical and Instrumental Assessment. As reported above, different scales were used to assess the pain features in ALS patients (Table 3). The short form of BPI was generally applied [97] while only few studies assessed the neuropathic origin of pain with specific questionnaires as DN4 or neuropathic pain scales [96] (Table 3). In most studies, the factors aggravating pain, such as depression and sleep disturbances, were also assessed.

Neurophysiological studies and in particular electromyography and electroneurography are routinely applied for diagnostic purposes to explore motor system in ALS patients [98] while the employment of methods for the specific assessment of nociceptive pathways functions was rarely reported though it would be useful to improve the knowledge about pain pathophysiology and its management. Contact heat evoked potentials were used to explore noxious stimuli conduction along the C-fibers in 60 ALS patients versus 60 controls, and no significant abnormality was found in patients corroborating the hypothesis of an intact nociceptive system [99]. These results were not confirmed in a CO2 laser evoked potentials (LEPs) study conducted in 23 ALS patients [100], who showed an increase in LEPs latencies but also in the amplitude of the earlier latency N1 potential. This is a contradictory result possibly explained by a probable dysfunction of the nociceptive pathways at subcortical level [101], coexisting with enhanced excitability of the nociceptive cortex as a result of motor cortex degeneration. In that study, 19 patients complained about pain, which was usually of the musculoskeletal type supporting the hypothesis that, also in the presence of signs of nociceptive system dysfunction, pain is an indirect consequence of motor impairment [100]. Small fiber involvement was demonstrated by skin biopsy. Weis et al. [92] found a significant reduction in the epidermal nerve fiber density in the distal calf of patients with ALS, which was recently confirmed in another study based on skin biopsy and Quantitative Sensory Testing (QST). In this last study, only patients with spinal onset, but not those with bulbar form, showed an impairment of the thermal sensitivity and distal C afferents [102]. Moreover, a sensitive axonal involvement may be a feature of ALS subtypes.

5.3. Possible Pathophysiological Mechanisms. Clinical studies seem to indicate the nonneuropathic origin of pain in the majority of ALS patients though the complexity of this multisystemic degenerative disorder may account for a dysfunction of the nociceptive system at both peripheral and central level. The neuropathic components of ALS-related pain can be present even in the early phases of the disease and worsen the musculoskeletal pain. The presence of the nociceptive afferents dysfunction in ALS is suggested by both skin biopsies and QST especially in the spinal onset phenotype $[18,102]$. In addition, the complex interaction between the motor and sensory cortex may cause disinhibition and hyperactivation of sensory functions in order to improve sensory-motor integration in a situation of motor failure [103, 104]. This could explain the increased amplitude of LEPs [100] and SEPs [105] observed in the early stages of the disease.

5.4. Current Evidence on Pain Therapeutic Management. A recent Cochrane review [106] reported that there is no evidence from randomized controlled trials about the management of pain in ALS so no guidelines on this important aspect of the disease are available for clinicians. In an 
TABLE 3: Summary of studies on the prevalence and features of pain among patients with amyotrophic lateral sclerosis.

\begin{tabular}{|c|c|c|c|c|c|}
\hline & Study design & $\begin{array}{l}\text { Number of patients } \\
\text { and controls }\end{array}$ & Assessment methods & Frequency of pain & Feature and location of pain \\
\hline $\begin{array}{l}\text { Ganzini et al. } \\
{[18]}\end{array}$ & Observational & 100 patients & $\begin{array}{l}\text { Interview to patients and } \\
\text { caregivers }\end{array}$ & $\begin{array}{l}\text { 19\% reporting } \\
\text { moderate to severe } \\
\text { pain }\end{array}$ & Not reported \\
\hline Jensen et al. [19] & Observational & $\begin{array}{l}193 \text { patients with } \\
\text { neuromuscular } \\
\text { disease } \\
\text { (30 ALS) }\end{array}$ & $\begin{array}{l}\text { Neuropathic pain scale, } \\
\text { Brief Pain Inventory, } \\
\text { quality of life (SF-36) }\end{array}$ & $\begin{array}{l}60 \% \text { of ALS } \\
\text { patients }\end{array}$ & $\begin{array}{l}\text { "Deep," "tiring," "sharp," } \\
\text { and "dull" } \\
\text { Localized in the back, leg, } \\
\text { shoulder, and neck (total of } \\
\text { patients with } \\
\text { neuromuscular disease) }\end{array}$ \\
\hline Ho et al. [20] & Retrospective & 193 patients & Standard medical records & $23 \%$ & Shoulder pain \\
\hline Chiò et al. [21] & Case control & 160 patients & Brief Pain Inventory & $56.9 \%$ & $\begin{array}{c}\text { Pain more frequent in the } \\
\text { extremities }\end{array}$ \\
\hline $\begin{array}{l}\text { Pagnini et al. } \\
{[22]}\end{array}$ & Observational & 40 patients & $\begin{array}{c}\text { Italian Pain Questionnaire, } \\
\text { McGill Quality of Life } \\
\text { Questionnaire }\end{array}$ & $51.2 \%$ & $\begin{array}{c}\text { "Nagging," } \\
\text { “sore," "periodic," } \\
\text { “annoying," "exhausting," } \\
\text { "enduring," } \\
\text { "debilitating," and } \\
\text { "worrying" } \\
\end{array}$ \\
\hline Rivera et al. [23] & Observational & 63 & Neuropathic pain scale & $50 \%$ & Neuropathic pain \\
\hline $\begin{array}{l}\text { Pizzimenti et al. } \\
{[24]}\end{array}$ & Observational & 36 & $\begin{array}{c}\text { Neuropathic Pain Symptom } \\
\text { Inventory } \\
(2 \text { items }) \\
\end{array}$ & $71 \%$ & $\begin{array}{c}\text { Localized in } \\
\text { scapular-humeral area and } \\
\text { lower limb }\end{array}$ \\
\hline $\begin{array}{l}\text { Wallace et al. } \\
{[25]}\end{array}$ & Case control & 42 & $\begin{array}{c}\text { Brief Pain Inventory } \\
\text { PainDETECT } \\
\text { Questionnaire }\end{array}$ & $85 \%$ & $\begin{array}{l}\text { Nonneuropathic: } \\
\text { cramping, aching, tiring, } \\
\text { sharp, and tender }\end{array}$ \\
\hline $\begin{array}{l}\text { Hanisch et al. } \\
{[26]}\end{array}$ & Case control & 46 & Brief Pain Inventory & $78 \%$ & Cramps \\
\hline $\begin{array}{l}\text { Moisset et al. } \\
{[27]}\end{array}$ & Observational & 93 & DN4 questionnaire & $66 \%$ & $9 \%$ neuropathic pain \\
\hline
\end{tabular}

observational study, 17 out of 36 ALS patients complaining about pain received treatment with nonsteroidal antiinflammatory drugs, opioid, or antiepileptics with unspecified results [24]. In another observational study, $63 \%$ of 91 ALS patients suffering from pain were under treatment in most of the cases with nonsteroidal anti-inflammatory drugs and nonopioid analgesics [21]. Cramps are currently treated by carbamazepine or phenytoin [107]. In a hospice study, where more than $80 \%$ of the patients received the analgesic therapy at least once a day, opioids offered benefit to about $70 \%$ of the patients with advanced motoneuronal disease $[108,109]$. The treatment of spasticity by intrathecal baclofen may also alleviate pain though this aspect was rarely considered [110]. In addition, although riluzole is actually indicated as the only available disease-modifying medication and confers a little survival advantage, the effects of symptomatic treatment on pain remain unclear [111]. Again, pain associated with ALS is believed to be largely due to immobility. Physiotherapy, stretching, and range of motion exercises used in combination with pharmacotherapies to prevent contractures and reduce cramping and spasticity can be effective for associated pain $[107,112]$.
5.5. Main Limitations of Present Studies and Future Directions. ALS is a complex disorder where pain is currently considered an important but not primary end point in current management. Studies on pain frequency in ALS present the limits to be conducted in single centers in small samples, to rarely have a reliable control population, to be frequently retrospective, and to use usually nonvalidated methods for pain evaluation so the real impact of pain symptoms on the global burden of the disease is still unknown. Neurophysiological examination is limited to standard examination of sensory neurography, and the few studies with neurophysiological techniques exploring the nociceptive and nonnociceptive somatosensory system were conducted in small cohorts of patients in different stages of the disease. Controlled randomized trials on different pain killers are still lacking, and pain was considered only in some studies focusing on the global management of ALS.

Considering the impact of pain on the total outcome of ALS, a systematic clinical approach with specific scale for pain features and invalidity should be used in patients who report painful symptoms. A neurophysiological assessment of sensory functions by means of somatosensory nociceptively 
and nonnociceptively evoked responses might complete the standard examination [98]. The effects of treatments on pain should be considered, and specific, controlled trials are needed.

Although Cannabis may potentially represent a therapeutic opportunity for many ALS symptoms including pain $[113,114]$, evidence on its efficacy is presently scarce and based only on one controlled study in a small patient group, with negative results on pain release [115]. Angiotensin-converting enzyme inhibitors may be also a potential approach to neurodegenerative disorders and neuropathic pain [116]. In addition, physical therapy and the other nonpharmacological approach would be finalized toward pain symptoms improvement.

\section{Other Rare Neurodegenerative Conditions}

6.1. Spinocerebellar Ataxia (SCA). Among the neurodegenerative hereditary cerebellar ataxia conditions, there are at least 36 different forms of autosomal dominant cerebellar ataxia (ADCA), 20 autosomal recessive cerebellar ataxia conditions, two X-linked ataxia conditions, and several forms of ataxia associated with mitochondrial defects [117].

A number of disease entities present with the ADCA phenotype such as spinocerebellar ataxia (SCA) conditions, dentatorubral-pallidoluysian atrophy, episodic ataxia, and autosomal dominant spastic ataxia. SCA conditions can be divided by the mode of inheritance into autosomal dominant, autosomal recessive, or sporadic conditions. There are many types of spinocerebellar ataxia and about 30 different gene mutations, 22 different genes, and 10 different gene loci have been identified, but the numbers continue to grow [118-120].

The definition of SCA conditions, despite significant progress in their understanding, is still imprecise, but the development of genetic profiling has made genetic classifications possible, which allows estimating the underlying etiology in $60 \%$ of the patients [121]. SCA disorders are a group of neurodegenerative disorders with clinical, genetic, and neuropathological heterogeneity being characterized by ataxia and other neurological signs such as oculomotor disturbances, cognitive deficits, pyramidal and extrapyramidal dysfunction, and bulbar, spinal, and peripheral nervous system involvement [122]. The prevalence of ADCA conditions is estimated to be around 3 in 100000, but it is highly variable depending upon the geographical area [123, 124].

As compared with other neurodegenerative disorders such as Parkinson's disease, quantitative and validated assessment tools are less developed [125]. The patients generally experience problems with mobility, usual activities, pain/discomfort, depression/anxiety, and self-care. Different population surveys have shown that 19 to $64 \%$ of patients report pain as a problem in selected SCA conditions [126]. In the same study, multivariate analysis revealed three independent predictors of subjective health status: ataxia severity, extent of noncerebellar involvement, and the presence of depressive syndrome. Although pain is not a primary invalidating factor in such patients, it may influence the quality of life as part of depression-related symptoms cohort and noncerebellar features.
In a recent systematic review reporting data from 1062 publications and 12141 patients with different neuromuscular disorders, pain was found to be reported in 1 among 30 SCA sufferers [127]. However, pain may often be underestimated though it can be severe when related to dystonia. In SCA conditions, pain can be misdiagnosed and mistreated but successfully ameliorated by, for example, botulinum toxin therapy [128].

There are currently no cures for SCA and treatments (pharmacological therapy and physiotherapy) target the symptoms such as pain, spasticity, tremor, stiffness, postural balance, gait disabilities, sleep problems, and depression. However, there are some very preliminary and nonvalidated data suggesting the use of umbilical cord mesenchymal stem cells in SCA [129].

6.2. Spinal Muscular Atrophy (SMA). Spinal muscular atrophy (SMA) is an autosomal, recessive, severe neuromuscular, degenerative disease characterized by loss of alpha motor neuron function in the spinal cord resulting in progressive proximal symmetrical muscle weakness often greater in the legs than in arms, atrophy, and paralysis and eventually in impairment of respiration and dysphagia. SMA is the second most common lethal, autosomal, recessive disorder in Caucasians with an incidence of approximately $1 / 6000$ and a carrier frequency of $1 / 50$ [130]. The muscle weakness can cause contracture formation, spinal deformity, limited mobility, and activities of daily living and eventually cause pain.

Engel et al. [131] found chronic pain in most patients classified as "other MND" including the CMT disease, all forms of spinal muscular atrophy, and many forms of mitochondrial and congenital myopathies. Pain was most frequently reported in the legs with a mild intensity (1.3, range $0-6$ on the $0-11$ numerical scale) [131].

\section{Conclusions}

Neurodegenerative diseases represent a social, medical, and economic problem and constitute a main field of interest for neurologists. Pain may be one of the most debilitating symptoms and a mode to express subjective discomfort and sufferance. Motor and sensory deficit may directly cause pain as in amyotrophic lateral sclerosis, Parkinson's disease, spinal cerebellar ataxia, and hereditary neuropathies where the subjective expression may be limited by the motor impairment. In demented patients, pain may be caused by different factors as age-related muscle skeletal degeneration, immobility, or neurodegeneration in brain areas involved in pain inhibition though subjective sufferance manifestation may be limited by cognitive impairment. The present review outlined a general medical carelessness with regard to pain as attention is especially pointed to the main illness symptoms. However, in many conditions such as Parkinson's disease, amyotrophic lateral sclerosis, and chronic familiar polyneuropathy, pain is largely represented among patients pending its specific assessment. Even in Alzheimer's disease, if special care is provided and specific scales are used, pain appears not to 
be a secondary problem but instead it appears worthy of full consideration. In rare conditions as Huntington's disease, pain expression may be also limited, and its causes would be underestimated and neglected. As a consequence of the scarce attention generally dedicated to pain, no controlled trials and specific treatment guidelines are available, and pain therapy is generally based on the symptomatic approach by analgesics and anti-inflammatory drugs without a systematic consideration of the causal mechanisms. Current evidences about the relevance of pain in neurodegenerative disorders indicate the opportunity of a full involvement of neurologists in pain management taking into consideration its causes and mechanisms giving special attention to predisposing factors symptoms, employing and validating specific scales performing the clinical and instrumental assessment of sensory functions promoting therapeutic trials by means of pharmacological and nonpharmacological approach. Considering the centrality of pain in individual suffering, the question "Do you feel, or did he/she feel pain?" followed by a careful observation and consideration of the contribution of painful symptoms to the global burden of the disease should be included in the routine assessment of neurodegenerative diseases to finalize the best therapeutic choice.

\section{Competing Interests}

The authors declare that there is no conflict of interests regarding the publication of this paper.

\section{References}

[1] A. G. Beiske, J. H. Loge, A. Rønningen, and E. Svensson, "Pain in Parkinson's disease: prevalence and characteristics," Pain, vol. 141, no. 1-2, pp. 173-177, 2009.

[2] Classification of Chronic Pain, "IASP task force on taxonomy," in Part III: Pain Terms, A Current List with Definitions and Notes on Usage, H. Merskey and N. Bogduk, Eds., pp. 209-214, IASP Press, Seattle, Wash, USA, 2nd edition, 1994.

[3] T. S. Jensen, R. Baron, M. Haanpää et al., "A new definition of neuropathic pain,” Pain, vol. 152, no. 10, pp. 2204-2205, 2011.

[4] M. Haanpää, N. Attal, M. Backonja et al., "NeuPSIG guidelines on neuropathic pain assessment," Pain, vol. 152, no. 1, pp. 14-27, 2011.

[5] R. D. Helme and S. J. Gibson, "The epidemiology of pain in elderly people," Clinics in Geriatric Medicine, vol. 17, no. 3, pp. 417-431, 2001.

[6] E. Scherder, K. Herr, G. Pickering, S. Gibson, F. Benedetti, and S. Lautenbacher, "Pain in dementia," Pain, vol. 145, no. 3, pp. 276-278, 2009.

[7] H. E. Barry, C. Parsons, A. P. Passmore, and C. M. Hughes, "Exploring the prevalence of and factors associated with pain: a cross-sectional study of community-dwelling people with dementia," Health and Social Care in the Community, vol. 24, no. 3, pp. 270-282, 2016.

[8] H. E. Barry, C. Parsons, A. Peter Passmore, and C. M. Hughes, "Pain in care home residents with dementia: an exploration of frequency, prescribing and relatives' perspectives," International Journal of Geriatric Psychiatry, vol. 30, no. 1, pp. 55-63, 2015.

[9] L. J. Hunt, K. E. Covinsky, K. Yaffe et al., "Pain in communitydwelling older adults with dementia: results from the national health and aging trends study," Journal of the American Geriatrics Society, vol. 63, no. 8, pp. 1503-1511, 2015.

[10] P. Werner, J. Cohen-Mansfield, V. Watson, and S. Pasis, "Pain in participants of adult day care centers: assessment by different raters," Journal of Pain and Symptom Management, vol. 15, no. 1, pp. 8-17, 1998.

[11] P. Mäntyselkä, S. Hartikainen, K. Louhivuori-Laako, and R. Sulkava, "Effects of dementia on perceived daily pain in homedwelling elderly people: a population-based study," Age and Ageing, vol. 33, no. 5, pp. 496-499, 2004.

[12] J. W. Shega, G. W. Hougham, C. B. Stocking, D. Cox-Hayley, and G. A. Sachs, "Pain in community-dwelling persons with dementia: frequency, intensity, and congruence between patient and caregiver report," Journal of Pain and Symptom Management, vol. 28, no. 6, pp. 585-592, 2004.

[13] S. Zwakhalen, R. Koopmans, P. Geels, M. Berger, and J. Hamers, "The prevalence of pain in nursing home residents with dementia measured using an observational pain scale," European Journal of Pain, vol. 13, no. 1, pp. 89-93, 2009.

[14] L. Nègre-Pagès, W. Regragui, D. Bouhassira, H. Grandjean, and O. Rascol, "Chronic pain in Parkinson's disease: the crosssectional French DoPaMiP survey," Movement Disorders, vol. 23, no. 10, pp. 1361-1369, 2008.

[15] G. Defazio, A. Gigante, P. Mancino, and M. Tinazzi, "The epidemiology of pain in Parkinson's disease," Journal of Neural Transmission, vol. 120, no. 4, pp. 583-586, 2013.

[16] P. Valkovic, M. Minar, H. Singliarova et al., "Pain in Parkinson's disease: a cross-sectional study of its prevalence, types, and relationship to depression and quality of life," PLOS ONE, vol. 10, no. 8, Article ID e0136541, 2015.

[17] M. Tinazzi, S. Recchia, S. Simonetto et al., "Muscular pain in Parkinson's disease and nociceptive processing assessed with $\mathrm{CO}_{2}$ laser-evoked potentials," Movement Disorders, vol. 25, no. 2, pp. 213-220, 2010.

[18] L. Ganzini, W. S. Johnston, and W. F. Hoffman, "Correlates of suffering in amyotrophic lateral sclerosis," Neurology, vol. 52, no. 7, pp. 1434-1440, 1999.

[19] M. P. Jensen, R. T. Abresch, G. T. Carter, and C. M. McDonald, "Chronic pain in persons with neuromuscular disease," Archives of Physical Medicine and Rehabilitation, vol. 86, no. 6, pp. 11551163, 2005.

[20] D. T. Ho, R. Ruthazer, and J. A. Russell, "Shoulder pain in amyotrophic lateral sclerosis," Journal of Clinical Neuromuscular Disease, vol. 13, no. 1, pp. 53-55, 2011.

[21] A. Chiò, A. Canosa, S. Gallo et al., "Pain in amyotrophic lateral sclerosis: a population-based controlled study," European Journal of Neurology, vol. 19, no. 4, pp. 551-555, 2012.

[22] F. Pagnini, C. Lunetta, P. Banfi et al., "Pain in amyotrophic lateral sclerosis: a psychological perspective," Neurological Sciences, vol. 33, no. 5, pp. 1193-1196, 2012.

[23] I. Rivera, S. Ajroud-Driss, P. Casey et al., "Prevalence and characteristics of pain in early and late stages of ALS," Amyotrophic Lateral Sclerosis and Frontotemporal Degeneration, vol. 14, no. 5-6, pp. 369-372, 2013.

[24] A. Pizzimenti, M. Aragona, E. Onesti, and M. Inghilleri, "Depression, pain and quality of life in patients with amyotrophic lateral sclerosis: a cross-sectional study, Functional Neurology, vol. 28, no. 2, pp. 115-119, 2013.

[25] V. C. J. Wallace, C. M. Ellis, R. Burman, C. Knights, C. E. Shaw, and A. Al-Chalabi, "The evaluation of pain in amyotrophic 
lateral sclerosis: a case controlled observational study," Amyotrophic Lateral Sclerosis and Frontotemporal Degeneration, vol. 15, no. 7-8, pp. 520-527, 2014.

[26] F. Hanisch, A. Skudlarek, J. Berndt, and M. E. Kornhuber, "Characteristics of pain in amyotrophic lateral sclerosis," Brain and Behavior, vol. 5, no. 3, Article ID e00296, 2015.

[27] X. Moisset, C. Cornut-Chauvinc, P. Clavelou, B. Pereira, R. Dallel, and N. Guy, "Is there pain with neuropathic characteristics in patients with amyotrophic lateral sclerosis? A cross-sectional study," Palliative Medicine, vol. 30, no. 5, pp. 486-494, 2016.

[28] C. E. van t'Hof, S. M. G. Zwakhalen, and J. P. H. Hamers, "Interventions after diagnosing pain in nursing home residents with dementia: the pilot implementation of an observational pain scale (PACSLAC-D)," Tijdschrift voor Gerontologie en Geriatrie, vol. 42, no. 2, pp. 67-78, 2011.

[29] J. Miró, S. Paredes, M. Rull et al., "Pain in older adults: a prevalence study in the Mediterranean region of Catalonia," European Journal of Pain, vol. 11, no. 1, pp. 83-92, 2007.

[30] C. Grimby, J. Fastbom, Y. Forsell, M. Thorslund, C. B. Claesson, and B. Winblad, "Musculoskeletal pain and analgesic therapy in a very old population," Archives of Gerontology and Geriatrics, vol. 29, no. 1, pp. 29-43, 1999.

[31] S. D. Horn, S. A. Bender, N. Bergstrom et al., "Description of the national pressure ulcer long-term care study," Journal of the American Geriatrics Society, vol. 50, no. 11, pp. 1816-1825, 2002.

[32] B. S. Black, T. Finucane, A. Baker et al., "Health problems and correlates of pain in nursing home residents with advanced dementia," Alzheimer Disease and Associated Disorders, vol. 20, no. 4, pp. 283-290, 2006.

[33] J. Kappesser, A. C. D. C. Williams, and K. M. Prkachin, "Testing two accounts of pain underestimation," Pain, vol. 124, no. 1-2, pp. 109-116, 2006.

[34] M. Kunz, S. Scharmann, U. Hemmeter, K. Schepelmann, and S. Lautenbacher, "The facial expression of pain in patients with dementia," Pain, vol. 133, no. 1-3, pp. 221-228, 2007.

[35] M. Kunz, V. Mylius, S. Scharmann, K. Schepelman, and S. Lautenbacher, "Influence of dementia on multiple components of pain," European Journal of Pain, vol. 13, no. 3, pp. 317-325, 2009.

[36] K. Herr, K. Bjoro, and S. Decker, “Tools for assessment of pain in nonverbal older adults with dementia: a state-of-the-science review," Journal of Pain and Symptom Management, vol. 31, no. 2, pp. 170-192, 2006.

[37] A. Corbett, W. Achterberg, B. Husebo et al., "An international road map to improve pain assessment in people with impaired cognition: the development of the Pain Assessment in Impaired Cognition (PAIC) meta-tool," BMC Neurology, vol. 14, article 229, 2014.

[38] R. Defrin, M. Amanzio, M. de Tommaso et al., "Experimental pain processing in individuals with cognitive impairment: current state of the science," Pain, vol. 156, no. 8, pp. 1396-1408, 2015.

[39] L. J. Cole, M. J. Farrell, E. P. Duff, J. B. Barber, G. F. Egan, and S. J. Gibson, "Pain sensitivity and fMRI pain-related brain activity in Alzheimer's disease," Brain, vol. 129, no. 11, pp. 2957-2965, 2006.

[40] L. J. Cole, M. Gavrilescu, L. A. Johnston, S. J. Gibson, M. J. Farrell, and G. F. Egan, “The impact of Alzheimer's disease on the functional connectivity between brain regions underlying pain perception," European Journal of Pain, vol. 15, no. 6, pp. 568.e1-568.el1, 2011.
[41] S. J. Gibson, X. Voukelatos, D. Ames, L. Flicker, and R. D. Helme, "An examination of pain perception and cerebral event-related potentials following carbon dioxide laser stimulation in patients with Alzheimer's disease and age-matched control volunteers," Pain Research and Management, vol. 6, no. 3, pp. 126-132, 2001.

[42] M. Yamamoto, T. Kachi, and A. Igata, "Pain-related somatosensory evoked potentials in dementia," Journal of the Neurological Sciences, vol. 137, no. 2, pp. 117-119, 1996.

[43] W. P. Achterberg, M. J. C. Pieper, A. H. van Dalen-Kok et al., "Pain management in patients with dementia," Clinical Interventions in Aging, vol. 8, pp. 1471-1482, 2013.

[44] E. Tan, N. Jokanovic, M. Koponen, D. Thomas, S. Hilmer, and J. S. Bell, "Prevalence of analgesic use and pain in people with and without dementia or cognitive impairment in aged care facilities: a systematic review and meta-analysis," Current Clinical Pharmacology, vol. 10, no. 3, pp. 194-203, 2015.

[45] Y. Haasum, J. Fastbom, L. Fratiglioni, I. Kåreholt, and K. Johnell, "Pain treatment in elderly persons with and without dementia: a population-based study of institutionalized and home-dwelling elderly," Drugs and Aging, vol. 28, no. 4, pp. 283-293, 2011.

[46] H. Lövheim, S. Karlsson, and Y. Gustafson, "The use of central nervous system drugs and analgesics among very old people with and without dementia," Pharmacoepidemiology and Drug Safety, vol. 17, no. 9, pp. 912-918, 2008.

[47] B. Ford, "Pain in Parkinson's disease," Movement Disorders, vol. 25, no. S1, pp. S98-S103, 2010.

[48] A. Truini, M. Frontoni, and G. Cruccu, "Parkinson's disease related pain: a review of recent findings," Journal of Neurology, vol. 260, no. 1, pp. 330-334, 2013.

[49] A. D. Ha and J. Jankovic, "Pain in Parkinson's disease," Movement Disorders, vol. 27, no. 4, pp. 485-491, 2012.

[50] A. Berardelli, A. Conte, G. Fabbrini et al., "Pathophysiology of pain and fatigue in Parkinson's disease," Parkinsonism and Related Disorders, vol. 18, no. 1, pp. S226-S228, 2012.

[51] M. Tinazzi, C. Del Vesco, G. Defazio et al., "Abnormal processing of the nociceptive input in Parkinson's disease: a study with $\mathrm{CO}_{2}$ laser evoked potentials," Pain, vol. 136, no. 1-2, pp. 117-124, 2008.

[52] M. P. G. Broen, M. M. Braaksma, J. Patijn, and W. E. J. Weber, "Prevalence of pain in Parkinson's disease: a systematic review using the modified QUADAS tool," Movement Disorders, vol. 27, no. 4, pp. 480-484, 2012.

[53] B. H. Quittenbaum and B. Grahn, "Quality of life and pain in Parkinson's disease: a controlled cross-sectional study," Parkinsonism and Related Disorders, vol. 10, no. 3, pp. 129-136, 2004.

[54] K. R. Chaudhuri, P. Martinez-Martin, A. H. Schapira et al., "International multicenter pilot study of the first comprehensive self-completed nonmotor symptoms questionnaire for Parkinson's disease: The NMSQuest study," Movement Disorders, vol. 21, no. 7, pp. 916-923, 2006.

[55] K. R. Chaudhuri, A. Rizos, C. Trenkwalder et al., "King's Parkinson's disease pain scale, the first scale for pain in PD: an international validation," Movement Disorders, vol. 30, no. 12, pp. 1623-1631, 2015.

[56] R. Djaldetti, A. Shifrin, Z. Rogowski, E. Sprecher, E. Melamed, and D. Yarnitsky, "Quantitative measurement of pain sensation in patients with Parkinson disease," Neurology, vol. 62, no. 12, pp. 2171-2175, 2004.

[57] A. Gerdelat-Mas, M. Simonetta-Moreau, C. Thalamas et al., "Levodopa raises objective pain threshold in Parkinson's disease: a RIII reflex study, Journal of Neurology, Neurosurgery and Psychiatry, vol. 78, no. 10, pp. 1140-1142, 2007. 
[58] M. Tinazzi, S. Recchia, S. Simonetto et al., "Hyperalgesia and laser evoked potentials alterations in hemiparkinson: evidence for an abnormal nociceptive processing," Journal of the Neurological Sciences, vol. 276, no. 1-2, pp. 153-158, 2009.

[59] V. Mylius, I. Engau, M. Teepker et al., "Pain sensitivity and descending inhibition of pain in Parkinson's disease," Journal of Neurology, Neurosurgery and Psychiatry, vol. 80, no. 1, pp. 24-28, 2009.

[60] S. Zambito Marsala, M. Tinazzi, R. Vitaliani et al., "Spontaneous pain, pain threshold, and pain tolerance in Parkinson's disease," Journal of Neurology, vol. 258, no. 4, pp. 627-633, 2011.

[61] A. Perrotta, G. Sandrini, M. Serrao et al., "Facilitated temporal summation of pain at spinal level in Parkinson's disease," Movement Disorders, vol. 26, no. 3, pp. 442-448, 2011.

[62] C. Brefel-Courbon, P. Payoux, C. Thalamas et al., "Effects of levodopa on pain threshold in Parkinson's disease: a clinical and positron emission tomography study," Movement Disorders, vol. 20, no. 12, pp. 1557-1563, 2005.

[63] C. Brefel-Courbon, F. Ory-Magne, C. Thalamas, P. Payoux, and O. Rascol, "Nociceptive brain activation in patients with neuropathic pain related to Parkinson's disease," Parkinsonism and Related Disorders, vol. 19, no. 5, pp. 548-552, 2013.

[64] E. G. Da Silva, M. A. Viana, and E. M. A. Barasnevicius Quagliato, "Pain in Parkinson's disease: analysis of 50 cases in a clinic of movement disorders," Arquivos de Neuro-Psiquiatria, vol. 66, no. 1, pp. 26-29, 2008.

[65] G. Defazio, M. Tinazzi, and A. Berardelli, "How pain arises in Parkinson's disease?" European Journal of Neurology, vol. 20, no. 12, pp. 1517-1523, 2013.

[66] M. Nolano, V. Provitera, A. Estraneo et al., "Sensory deficit in Parkinson's disease: evidence of a cutaneous denervation," Brain, vol. 131, no. 7, pp. 1903-1911, 2008.

[67] L. Kass-Iliyya, S. Javed, D. Gosal et al., "Small fiber neuropathy in Parkinson's disease: a clinical, pathological and corneal confocal microscopy study," Parkinsonism \& Related Disorders, vol. 21, no. 12, pp. 1454-1460, 2015.

[68] E. Scherder and M. Statema, "Huntington's disease," The Lancet, vol. 376, no. 9751, p. 1464, 2010.

[69] J. E. Andrich, M. Wobben, P. Klotz, O. Goetze, and C. Saft, "Upper gastrointestinal findings in Huntington's disease: patients suffer but do not complain," Journal of Neural Transmission, vol. 116, no. 12, pp. 1607-1611, 2009.

[70] M. de Tommaso, C. Serpino, O. Difruscolo et al., "Nociceptive inputs transmission in Huntington's disease: a study by laser evoked potentials," Acta Neurologica Belgica, vol. 111, no. 1, pp. 33-40, 2011.

[71] S. Baez, E. Herrera, O. Gershanik et al., "Impairments in negative emotion recognition and empathy for pain in Huntington's disease families," Neuropsychologia, vol. 68, pp. 158-167, 2015.

[72] S. A. Johnson, J. C. Stout, A. C. Solomon et al., "Beyond disgust: impaired recognition of negative emotions prior to diagnosis in Huntington's disease," Brain, vol. 130, no. 7, pp. 1732-1744, 2007.

[73] M. Moayedi, M. Liang, A. L. Sim, L. Hu, P. Haggard, and G. D. Iannetti, "Laser-evoked vertex potentials predict defensive motor actions," Cerebral Cortex, vol. 25, no. 12, pp. 4789-4798, 2015.

[74] G. Abbruzzese and A. Berardelli, "Sensorimotor integration in movement disorders," Movement Disorders, vol. 18, no. 3, pp. 231-240, 2003.

[75] J. G. Nutt, M. D. Muenter, A. Aronson, L. T. Kurland, and L. J. Melton III, "Epidemiology of focal and generalized dystonia in Rochester, Minnesota," Movement Disorders, vol. 3, no. 3, pp. 188-194, 1988.

[76] J. Chan, M. F. Brin, and S. Fahn, "Idiopathic cervical dystonia: clinical characteristics," Movement Disorders, vol. 6, no. 2, pp. 119-126, 1991.

[77] J. Jankovic, S. Leder, D. Warner, and K. Schwartz, "Cervical dystonia: clinical findings and associated movement disorders," Neurology, vol. 41, no. 7, pp. 1088-1091, 1991.

[78] P. D. Charles, C. H. Adler, M. Stacy et al., "Cervical dystonia and pain: Characteristics and treatment patterns from $\mathrm{CD}$ PROBE (Cervical Dystonia Patient Registry for Observation of OnabotulinumtoxinA Efficacy)," Journal of Neurology, vol. 261, no. 7, pp. 1309-1319, 2014.

[79] J. D. Blackie and A. J. Lees, "Botulinum toxin treatment in spasmodic torticollis," Journal of Neurology, Neurosurgery, and Psychiatry, vol. 53, no. 8, pp. 640-643, 1990.

[80] I. T. Lorentz, S. S. Subramaniam, and C. Yiannikas, “Treatment of idiopathic spasmodic torticollis with botulinum toxin A: a double-blind study on twenty-three patients," Movement Disorders, vol. 6, no. 2, pp. 145-150, 1991.

[81] O. Kutvonen, P. Dastidar, and T. Nurmikko, "Pain in spasmodic torticollis," Pain, vol. 69, no. 3, pp. 279-286, 1997.

[82] A. Perrotta, M. Bolla, M. Serrao et al., "Enhanced temporal pain processing in multiple system atrophy," Neuroscience Letters, vol. 555, pp. 203-208, 2013.

[83] M. Tinazzi, M. Valeriani, G. Squintani et al., "Nociceptive pathway function is normal in cervical dystonia: a study using laser-evoked potentials," Journal of Neurology, vol. 259, no. 10, pp. 2060-2066, 2012.

[84] I. Suttrup, D. Oberdiek, J. Suttrup, N. Osada, S. Evers, and M. Marziniak, "Loss of sensory function in patients with idiopathic hand dystonia," Movement Disorders, vol. 26, no. 1, pp. 107-113, 2011.

[85] F. Tison, G. K. Wenning, M. A. Volonte, W. R. Poewe, P. Henry, and N. P. Quinn, "Pain in multiple system atrophy," Journal of Neurology, vol. 243, no. 2, pp. 153-156, 1996.

[86] C. Colosimo, L. Morgante, A. Antonini et al., "Non-motor symptoms in atypical and secondary parkinsonism: the PRIAMO study," Journal of Neurology, vol. 257, no. 1, pp. 5-14, 2010.

[87] L. Kass-Iliyya, C. Kobylecki, K. R. Mcdonald, A. Gerhard, and M. A. Silverdale, "Pain in multiple system atrophy and progressive supranuclear palsy compared to Parkinson's disease," Brain and Behavior, vol. 5, no. 5, Article ID e00320, 2015.

[88] M. Stamelou, H. Dohmann, J. Brebermann et al., "Clinical pain and experimental pain sensitivity in progressive supranuclear palsy," Parkinsonism and Related Disorders, vol. 18, no. 5, pp. 606-608, 2012.

[89] L. P. Rowland and N. A. Shneider, "Amyotrophic lateral sclerosis," The New England Journal of Medicine, vol. 344, no. 22, pp. 1688-1700, 2001.

[90] M. R. Turner and M. Swash, "The expanding syndrome of amyotrophic lateral sclerosis: a clinical and molecular odyssey," Journal of Neurology, Neurosurgery and Psychiatry, vol. 86, no. 6, pp. 667-673, 2015.

[91] I. S. Wechsler, S. Brock, and A. Weil, "Amyotrophic lateral sclerosis with objective and subjective (neuritic) sensory disturbances," Archives of Neurology \& Psychiatry, vol. 21, no. 2, pp. 299-310, 1929.

[92] J. Weis, I. Katona, G. Müller-Newen et al., "Small-fiber neuropathy in patients with ALS," Neurology, vol. 76, no. 23, pp. 20242029, 2011. 
[93] M. Elamin, P. Bede, S. Byrne et al., "Cognitive changes predict functional decline in ALS: a population-based longitudinal study," Neurology, vol. 80, no. 17, pp. 1590-1597, 2013.

[94] M. E. Drake Jr., "Chronic pain syndrome in amyotrophic lateral sclerosis," Archives of Neurology, vol. 40, no. 7, pp. 453-454, 1983.

[95] G. De Benedittis, R. Massel, R. Nobili, and A. Pieri, “The Italian pain questionnaire," Pain, vol. 33, no. 1, pp. 53-62, 1988.

[96] D. Bouhassira, N. Attal, H. Alchaar et al., "Comparison of pain syndromes associated with nervous or somatic lesions and development of a new neuropathic pain diagnostic questionnaire (DN4)," Pain, vol. 114, no. 1-2, pp. 29-36, 2005.

[97] C. S. Cleeland and K. M. Ryan, "Pain assessment: global use of the Brief Pain Inventory," Annals of the Academy of Medicine Singapore, vol. 23, no. 2, pp. 129-138, 1994.

[98] B. R. Brooks, R. G. Miller, M. Swash, and T. L. Munsat, "El Escorial revisited: revised criteria for the diagnosis of amyotrophic lateral sclerosis," Amyotrophic Lateral Sclerosis and Other Motor Neuron Disorders, vol. 1, no. 5, pp. 293-299, 2000.

[99] Y.-S. Xu, J. Zhang, J.-Y. Zheng, S. Zhang, D.-X. Kang, and D.S. Fan, "Fully intact contact heat evoked potentials in patients with amyotrophic lateral sclerosis," Muscle \& Nerve, vol. 39, no. 6, pp. 735-738, 2009.

[100] I. L. Simone, R. Tortelli, V. Samarelli et al., "Laser evoked potentials in amyotrophic lateral sclerosis," Journal of the Neurological Sciences, vol. 288, no. 1-2, pp. 106-111, 2010.

[101] J. S. Lowe and N. Leigh, "Disorders of movement and system degenerations," in Greenfield's Neuropathology, D. I. Graham and P. L. Lantos, Eds., pp. 372-383, Oxford University Press, New York, NY, USA, 7th edition, 2002.

[102] A. Truini, A. Biasiotta, E. Onesti et al., "Small-fibre neuropathy related to bulbar and spinal-onset in patients with ALS," Journal of Neurology, vol. 262, no. 4, pp. 1014-1018, 2015.

[103] K. Rosenkranz, A. Pesenti, W. Paulus, and F. Tergau, "Focal reduction of intracortical inhibition in the motor cortex by selective proprioceptive stimulation," Experimental Brain Research, vol. 149, no. 1, pp. 9-16, 2003.

[104] K. Rosenkranz and J. C. Rothwell, "The effect of sensory input and attention on the sensorimotor organization of the hand area of the human motor cortex," The Journal of Physiology, vol. 561, no. 1, pp. 307-320, 2004.

[105] M. Hamada, R. Hanajima, Y. Terao et al., "Median nerve somatosensory evoked potentials and their high-frequency oscillations in amyotrophic lateral sclerosis," Clinical Neurophysiology, vol. 118, no. 4, pp. 877-886, 2007.

[106] J. Brettschneider, J. Kurent, and A. Ludolph, "Drug therapy for pain in amyotrophic lateral sclerosis or motor neuron disease," The Cochrane Database of Systematic Reviews, no. 6, Article ID CD005226, 2013.

[107] J. Mitchell and G. Borasio, "Amyotrophic lateral sclerosis," The Lancet, vol. 369, no. 9578, pp. 2031-2041, 2007.

[108] T. O’Brien, M. Kelly, and C. Saunders, "Motor neurone disease: a hospice perspective," British Medical Journal, vol. 304, no. 6825, pp. 471-473, 1992.

[109] Z. Simmons, "Management strategies for patients with amyotrophic lateral sclerosis from diagnosis through death," Neurologist, vol. 11, no. 5, pp. 257-270, 2005.

[110] S. McClelland, F. A. Bethoux, N. M. Boulis et al., "Intrathecal baclofen for spasticity-related pain in amyotrophic lateral sclerosis: efficacy and factors associated with pain relief," Muscle \& Nerve, vol. 37, no. 3, pp. 396-398, 2008.
[111] T. M. Jenkins, H. Hollinger, and C. J. McDermott, “The evidence for symptomatic treatments in amyotrophic lateral sclerosis," Current Opinion in Neurology, vol. 27, no. 5, pp. 524-531, 2014.

[112] A. S. Mayadev, M. D. Weiss, B. Jane Distad, L. S. Krivickas, and G. T. Carter, "The amyotrophic lateral sclerosis center: a model of multidisciplinary management," Physical Medicine and Rehabilitation Clinics of North America, vol. 19, no. 3, pp. 619-631, 2008.

[113] G. T. Carter and B. S. Rosen, "Marijuana in the management of amyotrophic lateral sclerosis," The American Journal of Hospice \& Palliative Care, vol. 18, no. 4, pp. 264-270, 2001.

[114] D. Amtmann, P. Weydt, K. L. Johnson, M. P. Jensen, and G. T. Carter, "Survey of cannabis use in patients with amyotrophic lateral sclerosis," American Journal of Hospice and Palliative Medicine, vol. 21, no. 2, pp. 95-104, 2004.

[115] M. Weber, B. Goldman, and S. Truniger, "Tetrahydrocannabinol (THC) for cramps in amyotrophic lateral sclerosis: a randomised, double-blind crossover trial," Journal of Neurology, Neurosurgery and Psychiatry, vol. 81, no. 10, pp. 1135-1140, 2010.

[116] P. Kaur, A. Muthuraman, and M. Kaur, "The implications of angiotensin-converting enzymes and their modulators in neurodegenerative disorders: current and future perspectives," ACS Chemical Neuroscience, vol. 6, no. 4, pp. 508-521, 2015.

[117] M. Mancuso, D. Orsucci, G. Siciliano, and U. Bonuccelli, "The genetics of ataxia: through the labyrinth of the Minotaur, looking for Ariadne's thread," Journal of Neurology, vol. 261, no. 2, pp. 528-541, 2014.

[118] K. Ishikawa, Y. Niimi, N. Sato, T. Amino, and H. Mizusawa, "Dissecting molecular mechanism of spinocerebellar ataxia type 31," Rinsho Shinkeigaku, vol. 51, no. 11, pp. 1122-1124, 2011.

[119] A. E. Harding, "Classification of the hereditary ataxias and paraplegias," The Lancet, vol. 321, no. 8334, pp. 1151-1155, 1983.

[120] S. Fujioka, C. Sundal, and Z. K. Wszolek, "Autosomal dominant cerebellar ataxia type III: a review of the phenotypic and genotypic characteristics," Orphanet Journal of Rare Diseases, vol. 18, pp. 8-14, 2013.

[121] A. Sailer and H. Houlden, "Recent advances in the genetics of cerebellar ataxias," Current Neurology and Neuroscience Reports, vol. 12, no. 3, pp. 227-236, 2012.

[122] L. Schöls, P. Bauer, T. Schmidt, T. Schulte, and O. Riess, "Autosomal dominant cerebellar ataxias: clinical features, genetics, and pathogenesis," The Lancet Neurology, vol. 3, no. 5, pp. 291-304, 2004.

[123] J. Sequeiros, S. Martins, and I. Silveira, "Epidemiology and population genetics of degenerative ataxias," in Handbook of Clinical Neurology, S. H. Subramony and A. Dürr, Eds., vol. 103 of Ataxic Disorders, chapter 14, pp. 227-251, Elsevier, Edinburgh, UK, 3rd edition, 2011.

[124] T. Matsuura, L. P. W. Ranum, V. Volpini et al., "Spinocerebellar ataxia type 10 is rare in populations other than Mexicans," Neurology, vol. 58, no. 6, pp. 983-984, 2002.

[125] J. Johansson, L. Forsgren, O. Sandgren, A. Brice, G. Holmgren, and M. Holmberg, "Expanded CAG repeats in Swedish spinocerebellar ataxia type 7 (SCA7) patients: effect of CAG repeat length on the clinical manifestation," Human Molecular Genetics, vol. 7, no. 2, pp. 171-176, 1998.

[126] A. Szende and A. Williams, Eds., Measuring Self-Reported Population Health: An International Perspective Based on EQ-5D, Euro-Qol Group, Budapest, Hungary, SpringMed Publishing, 2004. 
[127] M. Rossi, S. Perez-Lloret, L. Doldan et al., "Autosomal dominant cerebellar ataxias: a systematic review of clinical features," European Journal of Neurology, vol. 21, no. 4, pp. 607-615, 2014.

[128] N. Whaley and R. Uitti, "Clumsy gait and leg pain," in Movement Disorders: 100 Instructive Cases, S. Reich, Ed., pp. 239-244, Taylor \& Francis Group, Boca Raton, Fla, USA, 2008.

[129] X. Miao, X. Wu, and W. Shi, "Umbilical cord mesenchymal stem cells in neurological disorders: a clinical study," Indian Journal of Biochemistry and Biophysics, vol. 52, no. 2, pp. 140-146, 2015.

[130] T. W. Prior, P. J. Snyder, B. D. Rink et al., "Newborn and carrier screening for spinal muscular atrophy," American Journal of Medical Genetics A, vol. 152, pp. 1605-1607, 2010.

[131] J. M. Engel, D. Kartin, G. T. Carter, M. P. Jensen, and K. M. Jaffe, "Pain in youths with neuromuscular disease," American Journal of Hospice and Palliative Medicine, vol. 26, no. 5, pp. 405-412, 2009. 


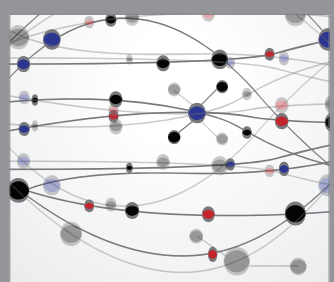

The Scientific World Journal
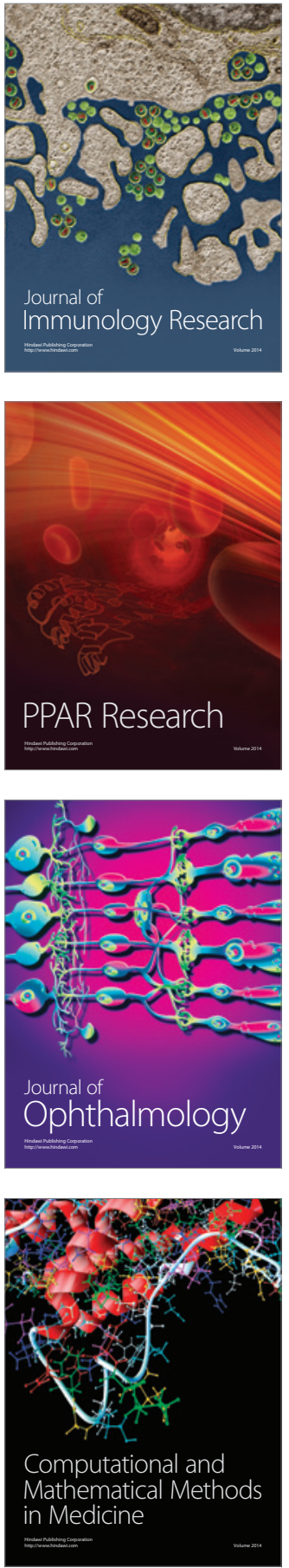

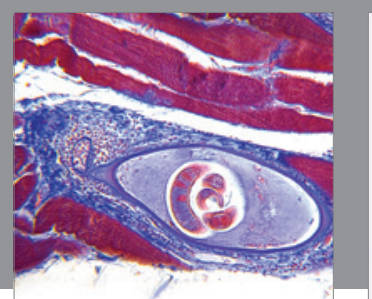

Gastroenterology Research and Practice

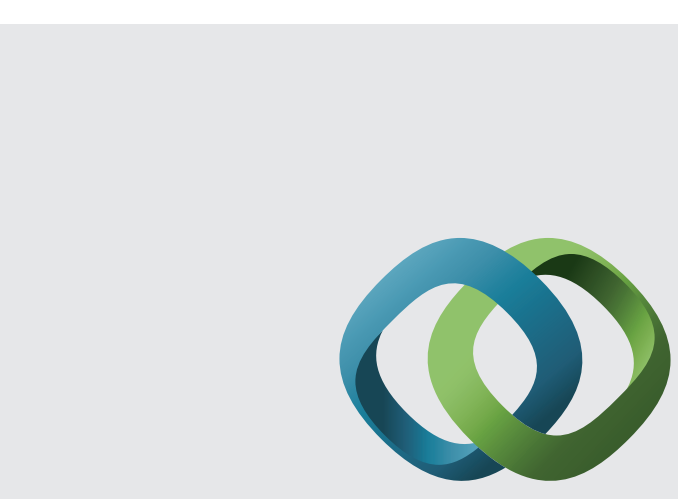

\section{Hindawi}

Submit your manuscripts at

http://www.hindawi.com
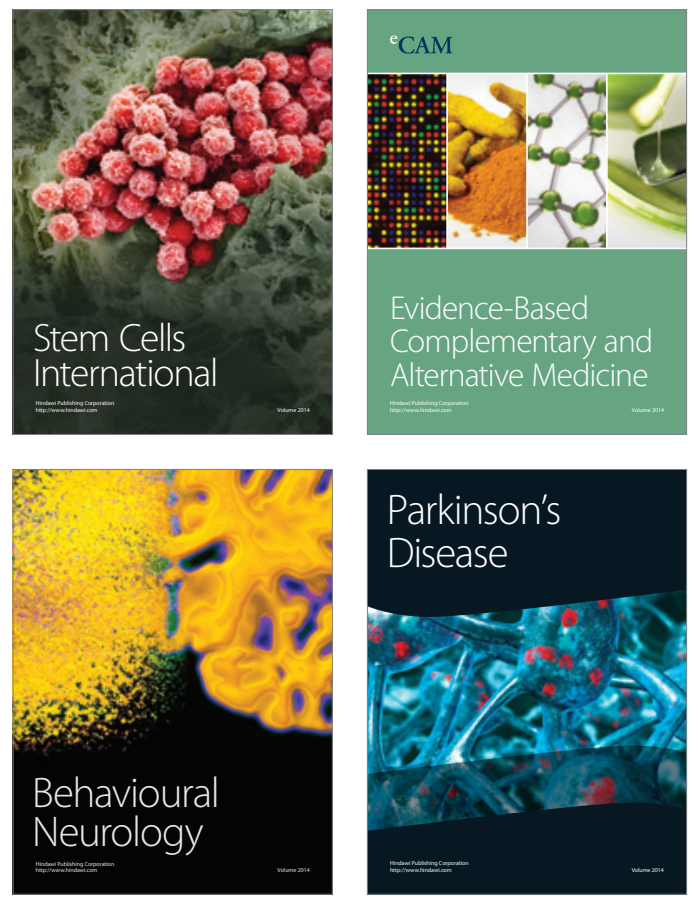
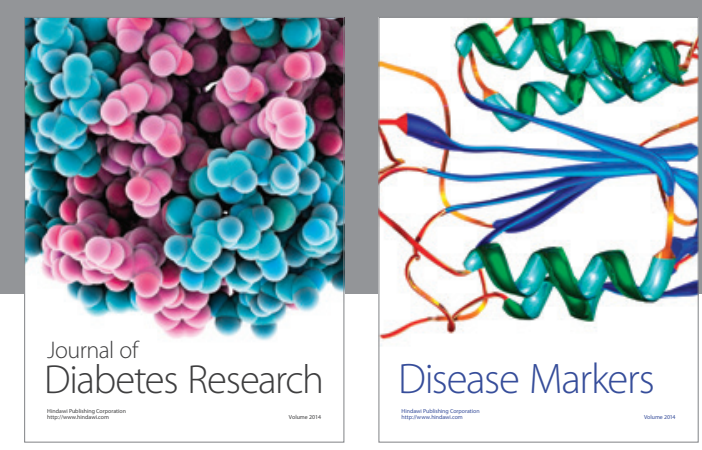

Disease Markers
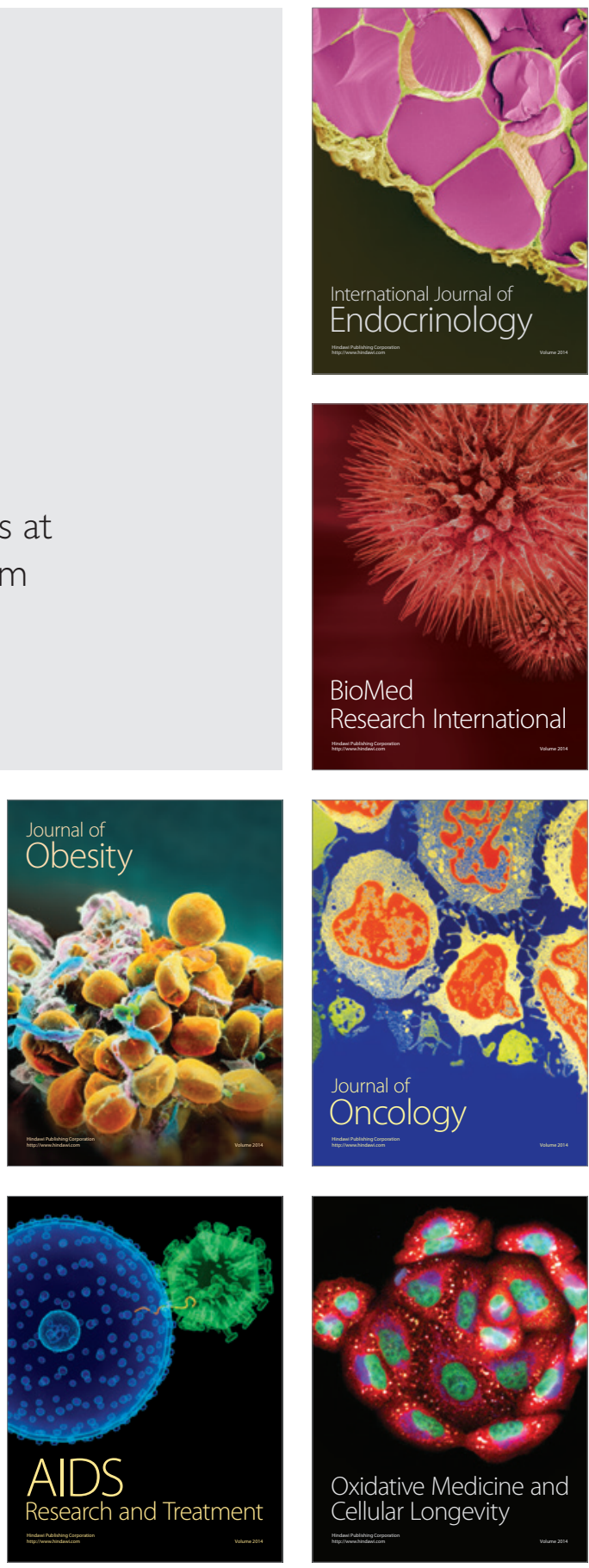